\title{
Pancreatobiliary Diseases Management by Endoscopic Ultrasonography/Endoscopic Retrograde Cholangiopancreatography Interface in Kurdistan Centre for Gastroenterology \& Hepatology
}

\author{
Taha Ahmed Mohmmad Al-karboly \\ Faculty of Medicine, University of Sulaimani, Iraqi Kurdistan, Iraq
}

Email address:

Alkarbolytaha@gmail.com (T. A. M. Al-karboly), Alkarbolytaha2007@yahoo.com (T. A. M. Al-karboly)

To cite this article:

Taha Ahmed Mohmmad Al-karboly. Pancreatobiliary Diseases Management by Endoscopic Ultrasonography/Endoscopic Retrograde Cholangiopancreatography Interface in Kurdistan Centre for Gastroenterology \& Hepatology. American Journal of Internal Medicine. Vol. 3, No. 6, 2015, pp. 217-223. doi: 10.11648/j.ajim.20150306.11

\begin{abstract}
Background: Pancreatobiliarydiseases (PBD) comprises diseases of both biliary system and pancreas and their diagnosis depends on appropriate clinical evaluation and investigations including imaging modalities like transabdominal ultrasound (TAUS), Magnetic resonance cholangiopancreatography (MRCP) and computed tomography (CT); Endoscopic ultrasound(EUS) have been found to be more sensitive than other imaging modality for detecting PBD, and less invasive than endoscopic retrograde cholangiopancreatography (ERCP). Aim of study: To compare the sensitivity and specificity of EUS with other imaging studies like ERCP, TAUS, CT scan, and MRCP/MRI for diagnosing PBD. Patients \& Methods: This study conducted in Kurdistan Centre for Gastroenterology and Hepatology (KCGH) from December 2013 through December 2014, after approval of institutional board ethical committee and taking written informed consents from all patients. A total number of 100 patients were enrolled in the study. We calculated the sensitivity, specificity, positive predictive value (PPV), negative predictive value (NPV), and accuracy of EUS, MRCP, and TAUS for PBD (benign \& malignant). ERCP was used as a reference standard for comparison. Results: $60 \%$ were females and $40 \%$ were males; the main presenting symptoms were combined abdominal pain and obstructive jaundice. The sensitivity, specificity, PPV, NPV, and accuracy of EUS for detecting benign biliary diseases like (bile duct stone and its complications) were $96.1 \%, 65.2 \%, 86 \%, 83.3 \%$, and $89 \%$, respectively; and for detecting pancreatobiliary tumors (PBT) were $84.6 \%, 97.7 \%, 84.6 \%, 97.7 \%$, and $96 \%$, respectively. The sensitivity of TAUS, MRCP for diagnosing biliary diseases were $58 \%$, and $60 \%$, respectively; and their sensitivity for detecting PBT were $37.5 \%$, and $50 \%$, respectively. The comparison between CT scan and ERCP was not feasible statistically. Conclusion: EUS has a higher sensitivity in comparison to other imaging modalities in detecting PBD; we can depend on it in selecting patients for therapeutic ERCP, in order to avoid unnecessary ERCP and its complications. The sensitivity and specificity of EUS in KCGH is comparable to other studies elsewhere.
\end{abstract}

Keywords: PBD, EUS, ERCP, MRCP, KCGH (Kurdistan Centre for Gastroenterology \& Hepatology), Sulaimani

\section{Introduction}

Pancreatobiliarydiseases (PBD) comprises diseases of the biliary system and pancreas. Management of PBD depends on proper clinical evaluation (with history \& proper physical examination), laboratory investigations, imaging, and endoscopic evaluation like endoscopic ultrasonography (EUS) and endoscopic retrograde cholangiopancreatography (ERCP). Patients with PBD might be asymptomatic identified incidentally or symptomatic, those who are symptomatic might have jaundice (obstructive) or abdominal pain or other symptoms like nausea, pruritus.etc ${ }^{[1]}$. Imaging plays an important role in differentiating medical from surgical causes of $\mathrm{PB}$, latter (surgical PBD) usually needs intervention either endoscopically or surgically ${ }^{[1]}$.

Invention of TAUS (gray scale) and ERCP in the mid 1970s boostered the management of PBD ${ }^{[2]}$; however ERCP was invasive procedure with significant morbidity and mortality and TAUS neither highly sensitive nor specific for diagnosing PBD. With introduction of MRCP and EUS new 
armamentarium were added to already available imaging for management of pancreatobiliary diseases ${ }^{[2]}$.

Transabdominal ultrasound (TAUS) can detect only 50$75 \%$ of $\mathrm{CBD}$ stones ${ }^{[3]}$, and nearly $75 \%$ of dilated common bile duct $(\mathrm{CBD})^{[4]}$.

Computed tomography (CT scan), can be used for detecting complications of gallstones such as abscess, perforation of CBD or Gallbladder, and pancreatitis [5]; MRCP has a sensitivity (93\%) and specificity (94\%) in comparison with ERCP, and it provide good information for more distal extra hepatic portion of the bile duct ${ }^{[6]}$; Endoscopic ultrasonography can be used for CBD stone diagnosis and has been found to be superior to $\mathrm{MRCP}^{[1]}$.

Gastrointestinal endosonography introduced in the mid1970 s, and began to be used practically in the mid-1980s ${ }^{[7]}$. Endoscopes of EUS generally of two types, radial (or sector) and linear (or convex array). The linear echo-endoscope is beneficial for both diagnostic and therapeutic applications ${ }^{[8]}$. As a diagnostic modality, EUS has been used to evaluate diseases or lesions involving the Pancreatobiliary tree, the esophagus, the stomach, the rectum, the left adrenal gland, the liver (especially left lobe), and the posterior mediastinum [9]. As a therapeutic modality the two most important indications are in celiac plexus neurolysis and celiac plexus block among others ${ }^{[10]}$.

Magnetic Resonance Cholangiopancreatography is a special type of MRI, used to study biliary and pancreatic ducts; it is largely replacing diagnostic role of ERCP, as it does not need contrast enhancement in the ductal system, thus, the morbidity associated with endoscopic procedures and contrast materials is avoided. But it cannot be used for intervention yet ${ }^{[1]}$. The addition of MRI to MRCP can be used for differentiating benign and malignant strictures of biliary system and assessing resectability of pancreatobiliary tumors ${ }^{[12]}$.

Aim of study: To compare the sensitivity and specificity of EUS with other imaging studies like ERCP, TAUS, CT scan, and MRCP/MRI for diagnosing PBD.

\section{Patients and Methods}

\subsection{Study Design and Setting}

A prospective case-series study was carried out in $\mathrm{KCGH}-$ Sulaimani city, which serves as a tertiary referral center for the Sulaimani governorate, in addition to referrals from other governorates of Iraqi Kurdistan region and Iraq.

\subsection{Selection of Cases}

This study was carried out from December 2013 through December 2014, one hundred patients were included (60 females and 40 males); we included patients referred for ERCP and had performed EUS to evaluate pancreatobiliary diseases. Patients with already diagnosed \& managed PBD and those with a known malignancy anywhere in the body were excluded. The interval between EUS and MRCP was 37 days.

\subsection{Data Collection and Information}

Our study commenced after approval from Institutional Board for medical studies. A written informed consents were taken from all patients, data collected from patients through interviewing by questionnaire.

\subsection{Interpretation of Results}

Demographic data were collected. Total serum bilirubin (TSB) of more than $1.5 \mathrm{mg} / \mathrm{dl}$ regarded as abnormal. direct hyperbilirubinemia was considered obstructive after confirmation by elevated Alkaline phosphatase (ALP) of more than 3.5-fold of upper normal, and elevated aspartate and alanine aminotransferases (AST and ALT) means more than $19 \mathrm{U} / \mathrm{L}$ in female and more than $30 \mathrm{U} / \mathrm{L}$ in male. Viral screen was performed for all patients; two patients have had inactive chronic carrier state of hepatitis B virus and only one patient with low titre hepatitis c virus ( $\mathrm{HCV}$ ) by polymerase chain reaction. Dilated common bile duct was defined by more than $6 \mathrm{~mm}$ in TAUS and EUS $(>7 \mathrm{~mm}$ in cholecystectomized patients), more than $8 \mathrm{~mm}$ in CT scan and MRI/MRCP, and more than $9 \mathrm{~mm}$ in $\mathrm{ERCP}^{[13,14,15]}$.

\subsection{Endoscopic Intervention and Type of Machine Used}

Endoscopic ultrasound and ERCP were performed by certified gastroenterologists at $\mathrm{KCGH}$, The diagnosis of choledocholithiasis was confirmed only if stones, stone fragment or sludge could be extracted out of the ampulla during ERCP. The machine which had been used for ERCP examination was (Olympus EXERA-I) with a video processor (CV-160), the machine used for EUS examination was (Olympus LUCERA) with a video processor (CV-260), ultrasound processor (EU-ME-1), and a linear probe of a version (GF-UCT260-AL5).

\subsection{Statistical Analysis}

All patients' data analyzed using computerized statistical software; Statistical Package for Social Sciences (SPSS) version 17. Descriptive statistics presented as (mean \pm standard deviation), frequencies and percentages. Multiple contingency tables conducted and appropriate statistical tests performed. Analysis of variance (ANOVA) was used to demonstrate the difference between different means. Validity of different tests was calculated by $2 \times 2$ tables. Level of significance ( $\mathrm{p}$ value) set at $\leq 0.05$ and the results presented as tables and or graphs.

\subsection{Statistical Definition ${ }^{[16]}$}

Sensitivity is the ability of a test to correctly classify an individual as 'diseased' (Probability of being test positive when disease present). Sensitivity $=$ (true positive) $/$ (true positive + false negative). Specificity is the ability of a test to correctly classify an individual as disease free (Probability of being test negative when disease absent). Specificity $=$ (true negative) / (true negative + false positive). Positive predictive value is the percentage of patients with a positive test who 
actually have the disease. PPV $=$ (true positive) $/$ (true positive + false positive). Negative predictive value is the percentage of patients with a negative test who do not have the disease. NPV = (true negative) / (false negative + true negative). Accuracy is how close a measured value is to the actual (true) value.

\section{Results}

A Total of one hundred patients were enrolled in present study with a mean age of $55 \pm 19$ years, patients with age $\geq 70$ years were more prevalent. Females $(60 \%)$ were more than males $(40 \%)$. As demonstrated in table (1).

Table 1: Demographic characteristics of studied patients.

\begin{tabular}{llll}
\hline demographic data & (No.) & Total (\%) \\
\hline \multirow{2}{*}{ Gender } & Female & 60 & 100 \\
& male & 40 & \\
& $<30$ & 10 & \\
& $30-39$ & 16 & 100 \\
Age (years) & $40-49$ & 15 & \\
& $50-59$ & 14 & \\
& $60-69$ & 15 & \\
& $\geq 70$ & 30 & 100 \\
thnicity & Kurdish & 77 & \\
& Arabic & 21 & \\
\hline
\end{tabular}

Most of patients presented with combined abdominal pain and jaundice (43\%), followed by abdominal pain (40\%) and obstructive jaundice (17\%) as illustrated in table (2).

Table 2: Initial presenting symptoms of studied patients.

\begin{tabular}{lll}
\hline Presenting symptoms & $\begin{array}{l}\text { Number and } \\
\text { percentage }\end{array}$ & Total \\
\hline Jaundice and abdominal pain & 43 & \\
Abdominal pain & 40 & 100 \\
Jaundice & 17 & \\
\hline
\end{tabular}

Table 3 demonstrates that $66 \%$ of patients had past history of surgery.

Table 3: Past surgical history of studied patients.

\begin{tabular}{lll}
\hline Past history & No. & $\%$ \\
\hline Past surgical history & & \\
\hline No & 66 & 66.0 \\
Cholecystectomy & 18 & 18.0 \\
Gastroduodenal surgery & 2 & 2.0 \\
Pancreatic surgery & 2 & 2.0 \\
Bile duct surgery & 1 & 1.0 \\
Extra-abdominal surgery & 11 & 11.0 \\
Total & 100 & 100.0 \\
\hline
\end{tabular}

Results of Oesophago-Gastro-Duodenoscopy (OGD) were abnormal among 15 patients (antral gastritis in 8 patients, non complicated duodenal ulcer in 3 patients and gastroesophageal reflux in 4 patients). Detailed diagnosis of Biliary diseases by ERCP revealed that 50 patients had $\mathrm{CBD}$ stone, and the others as illustrated in table 4. Among 10 patients with PB tumor diagnosed by ERCP, seven patients had pancreatic tumor, two patients with liver cancer and one patient with cholangiocarcinoma, as illustrated in table 4.

Table 4: Findings of different diagnostic tools in studied patients.

\begin{tabular}{|c|c|c|}
\hline Diagnostic tool & No. & $\%$ \\
\hline \multicolumn{3}{|l|}{ Oesophagogastro-duodenoscopy } \\
\hline Normal & 85 & 85.0 \\
\hline Abnormal & 15 & 15.0 \\
\hline Total & 100 & 100.0 \\
\hline \multicolumn{3}{|l|}{ Transabdominal ultrasound } \\
\hline Normal & 13 & 34.2 \\
\hline Dilated common bile duct & 20 & 52.6 \\
\hline Suspected PB Tumor & 5 & 13.2 \\
\hline Total & 38 & 100.0 \\
\hline \multicolumn{3}{|l|}{ Computed tomography scan } \\
\hline Normal & 3 & 27.3 \\
\hline Dilated common bile duct & 7 & 63.6 \\
\hline Suspected PB tumor & 1 & 9.1 \\
\hline Total & 11 & 100.0 \\
\hline \multicolumn{3}{|c|}{ Magnetic resonance cholangio-pancreatography } \\
\hline Normal & 2 & 14.3 \\
\hline Dilated common bile duct & 10 & 71.4 \\
\hline Suspected PB tumor & 2 & 14.3 \\
\hline Total & 14 & 100.0 \\
\hline \multicolumn{3}{|l|}{ Endoscopic ultrasonography } \\
\hline Normal & 10 & 10.0 \\
\hline Dilated common bile duct and stone & 79 & 79.0 \\
\hline Suspected PB tumor & 11 & 11.0 \\
\hline Total & 100 & 100.0 \\
\hline \multicolumn{3}{|c|}{ Endoscopic retrograde cholangiopancreatography } \\
\hline Normal & 17 & 17.0 \\
\hline Dilated common bile duct and stone & 73 & 73.0 \\
\hline Suspected PB Tumor & 10 & 10.0 \\
\hline Total & 100 & 100.0 \\
\hline
\end{tabular}

$\mathrm{PB}=$ Pancreatobiliary

ANOVA analysis revealed no significant differences in age and pain severity between normal, biliary diseases and pancreatobiliary tumor patients, on other hand, jaundice duration mean was significantly higher among tumor patients ( $\mathrm{P}$ value $=0.01$ ), as illustrated in table 5.

Table 5: Analysis of age, jaundice duration and severity of pain means according to final diagnosis by ERCP.

\begin{tabular}{llll}
\hline $\begin{array}{l}\text { Final Diagnosis } \\
\text { by ERCP }\end{array}$ & Age & $\begin{array}{l}\text { Jaundice } \\
\text { duration (weeks) }\end{array}$ & $\begin{array}{l}\text { Pain Severity } \\
\text { (Pain scale) }\end{array}$ \\
\hline & Mean \pm SD & Mean \pm SD & Mean \pm SD \\
\hline $\begin{array}{l}\text { Normal } \\
\text { Biliary diseases }\end{array}$ & $52 \pm 19.9$ & $3.6 \pm 2.6$ & $5.9 \pm 1$ \\
$\begin{array}{l}\text { Pancreatobiliary } \\
\text { tumors }\end{array}$ & $55.7 \pm 15.3$ & $5.3 \pm 5$ & $5.7 \pm 1$ \\
$\begin{array}{l}\text { ANOVA } \\
\text { (P value) }\end{array}$ & 0.8 & 0.01 & $4.5 \pm 1$ \\
\hline
\end{tabular}




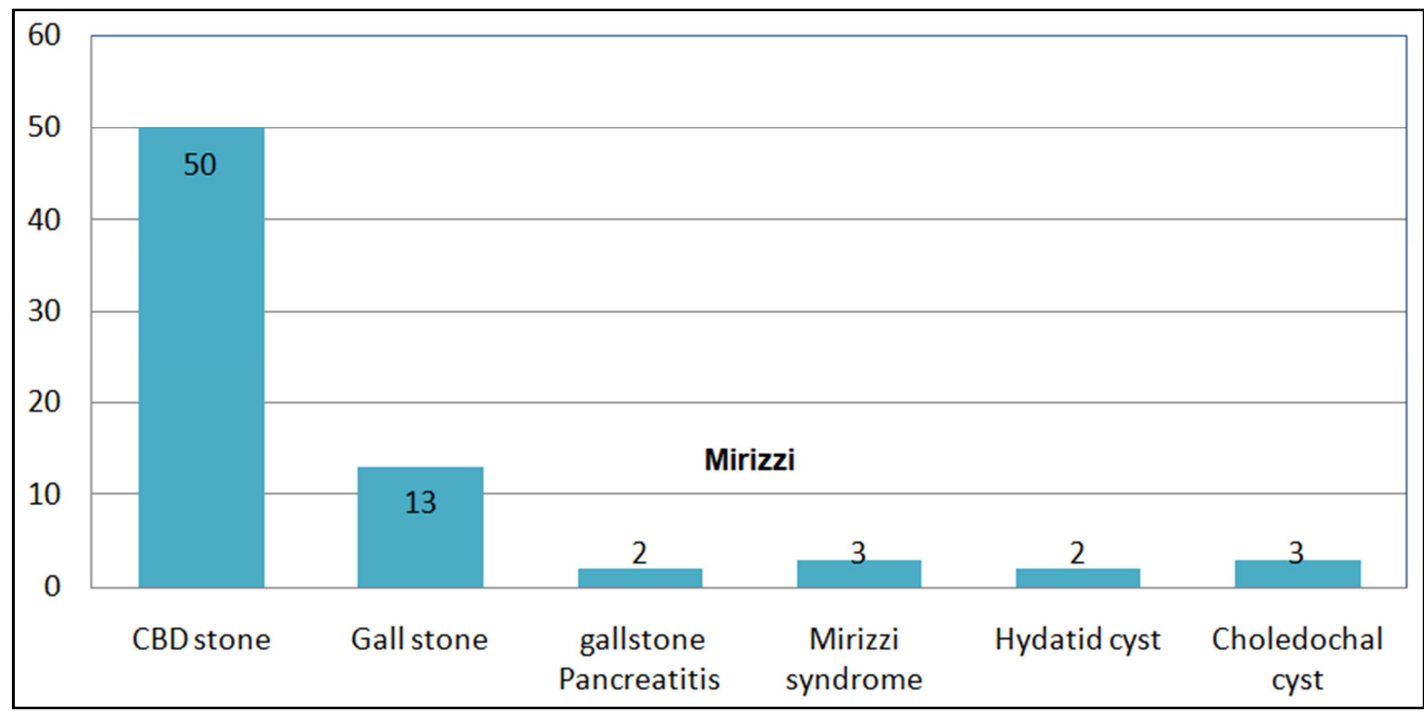

Figure 1: Categories of diseases under the title of Billiary disease patients by $E R C P(N=100) ;(C B D=$ common bile duct $)$.

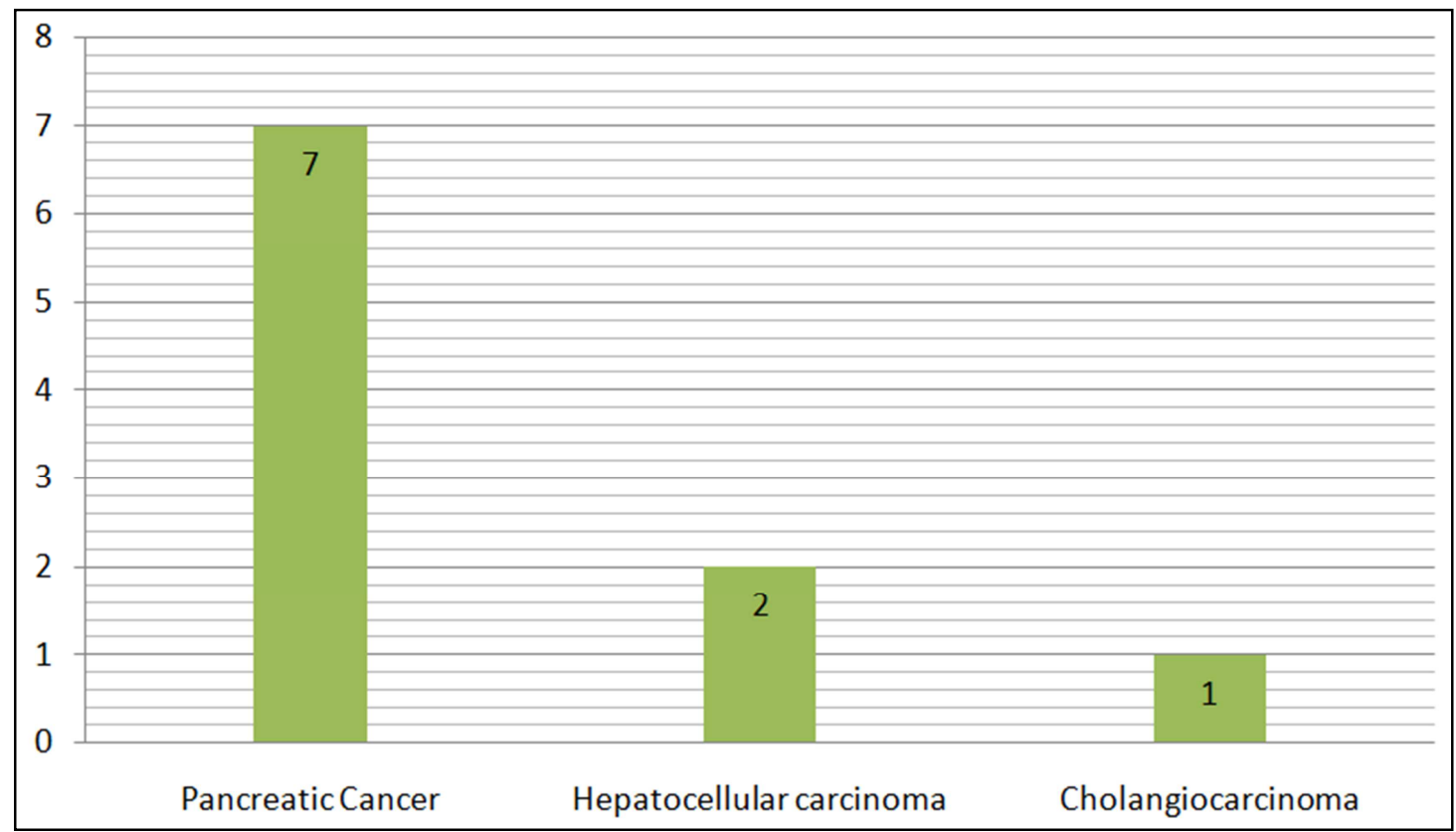

Figure 2: An ERCP spectrum of pancreatobiliary tumors.

Sensitivity of EUS in diagnosing biliary diseases was $96.1 \%$, specificity $65.2 \%$ and accuracy was $89 \%$, as illustrated in table 6 .

Table 6: Validity of EUS vs. ERCP in diagnosing biliary diseases.

\begin{tabular}{|c|c|c|c|c|}
\hline & \multicolumn{4}{|c|}{ ERCP } \\
\hline & & Positive & Negative & Total \\
\hline \multirow[t]{8}{*}{ EUS } & Positive & 74 & 8 & 82 \\
\hline & Negative & 3 & 15 & 18 \\
\hline & Total & 77 & 23 & 100 \\
\hline & \multicolumn{4}{|c|}{ Sensitivity $96.1 \%$} \\
\hline & \multicolumn{4}{|c|}{ Specificity $65.2 \%$} \\
\hline & \multicolumn{4}{|c|}{ Accuracy $89 \%$} \\
\hline & \multicolumn{4}{|c|}{ Positive predictive value $86 \%$} \\
\hline & \multicolumn{4}{|c|}{ Negative predictive value $83.3 \%$} \\
\hline
\end{tabular}

Sensitivity of Transabdominal ultrasound (TAUS) in diagnosing biliary diseases was $58 \%$, specificity $42.8 \%$ and accuracy was $55.2 \%$, as illustrated in table 7 .

Table 7: Validity of TAUS vs. ERCP in diagnosing biliary diseases.

\begin{tabular}{|c|c|c|c|c|}
\hline & \multicolumn{4}{|c|}{ ERCP } \\
\hline & & Positive & Negative & Total \\
\hline \multirow[t]{8}{*}{ TAUS } & Positive & 18 & 4 & 22 \\
\hline & Negative & 13 & 3 & 16 \\
\hline & Total & 31 & 7 & 18 \\
\hline & \multicolumn{4}{|c|}{ Sensitivity $58 \%$} \\
\hline & \multicolumn{4}{|c|}{ Specificity $42.8 \%$} \\
\hline & \multicolumn{4}{|c|}{ Accuracy $55.2 \%$} \\
\hline & \multicolumn{4}{|c|}{ Positive predictive value $90.2 \%$} \\
\hline & \multicolumn{4}{|c|}{ Negative predictive value $42.8 \%$} \\
\hline
\end{tabular}


Sensitivity of MRCP/MRI in diagnosing biliary diseases was $60 \%$, specificity $50 \%$ and accuracy was $57.1 \%$, as illustrated in table 8 .

Table 8: Validity of MRCP/MRI vs. ERCP in diagnosing biliary diseases.

\begin{tabular}{lllll}
\hline \multicolumn{5}{c}{ ERCP } \\
\hline MRCP & Positive & Negative & Total \\
\hline MRI & Positive & 6 & 2 & 8 \\
& Negative & 4 & 2 & 6 \\
& Total & 10 & 4 & 14 \\
& Sensitivity $60 \%$ & & \\
& Specificity $50 \%$ & & \\
& Accuracy $57.1 \%$ & \\
& Positive predictive value $75 \%$ & \\
& Negative predictive value 33.3\% & \\
\hline
\end{tabular}

Sensitivity of EUS in diagnosing suspected PB tumors was $84.6 \%$, specificity $97.7 \%$ and accuracy was $96 \%$, as illustrated in table 9 .

Table 9: Validity of EUS vs. ERCP in diagnosing pancreatobiliary tumors.

\begin{tabular}{|c|c|c|c|c|}
\hline & \multicolumn{4}{|c|}{ ERCP } \\
\hline & & Positive & Negative & Total \\
\hline \multirow[t]{8}{*}{ EUS } & Positive & 11 & 2 & 13 \\
\hline & Negative & 2 & 85 & 87 \\
\hline & Total & 13 & 87 & 100 \\
\hline & \multicolumn{4}{|c|}{ Sensitivity $84.6 \%$} \\
\hline & \multicolumn{4}{|c|}{ Specificity $97.7 \%$} \\
\hline & \multicolumn{4}{|c|}{ Accuracy $96 \%$} \\
\hline & \multicolumn{4}{|c|}{ Positive predictive value $84.6 \%$} \\
\hline & \multicolumn{4}{|c|}{ Negative predictive value $97.7 \%$} \\
\hline
\end{tabular}

Table 10 reveals sensitivity of TAUS was $37,5 \%$ in detecting PB tumors with specificity of $93,9 \%$.

Table 10: Validity of TAUS vs. ERCP in diagnosing Pancreatobiliary tumors.

\begin{tabular}{lllll}
\hline \multicolumn{5}{c}{ ERCP } \\
\hline \multirow{5}{*}{ TAUS } & Positive & Negative & Total \\
\hline & Positive & 3 & 2 & 5 \\
& Negative & 5 & 28 & 33 \\
& Total & 8 & 30 & 38 \\
& Sensitivity $37.5 \%$ & & \\
& Specificity $93.3 \%$ & & \\
& Accuracy $93.9 \%$ & \\
& Positive predictive value $60 \%$ & \\
& Negative predictive value $84.8 \%$ & \\
\hline
\end{tabular}

Sensitivity of MRCP/MRI in diagnosing PB tumors was $50 \%$, specificity $91.6 \%$ and accuracy was $85.7 \%$, as illustrated in table 11 .

Table 11: Validity of MRCP/MRI vs. ERCP in Pancreatobiliary tumors.

\begin{tabular}{lllll}
\hline & \multicolumn{5}{c}{ ERCP } \\
\hline \multirow{2}{*}{ MRCP/MRI } & Positive & Negative & Total \\
& Positive & 1 & 1 & 2 \\
& Negative & 1 & 11 & 12 \\
& Total & 2 & 12 & 14 \\
& Sensitivity 50\% & & \\
& Specificity 91.6\% & \\
& Accuracy 85.7\% & \\
& Positive predictive value 50\% & \\
& Negative predictive value 91.6\% & \\
\end{tabular}

\section{Discussions}

Various invasive and non-invasive diagnostic modalities are available for PBD, thus we need to be careful in selecting an appropriate modality in order to reduce complications of unnecessary invasive procedures and saving time and cost.

In this study number of patients who underwent noninvasive diagnostic procedures were 38, 14, and 11 for TAUS, MRCP/MRI, and CT scan respectively; which made their comparison to EUS prone to inaccuracy; and basically we could not compare CT scan with ERCP (assuming that ERCP result used as a definite diagnosis), as their number were too little to do a statistical analysis.

Biliarypancreatic diseases were found in 73 cases (ERCP result) include CBD stone, gallstones,gallstone pancreatitis, Mirizzi syndrome, hydatid cysts ( 2 cases were found, one of them in the liver compressing CBD and another one was intrabiliary rupture), and bile duct cysts; while suspected tumor were found in 10 cases and include suspected pancreatic and periampullary tumor, hepatocellular cancer, and cholangiocarcinoma, as shown in detail in the figures (1\& 2).

Three percent of patients found to have Mirizzi syndrome during ERCP, which is high in comparison to a study done by Yonetci et al ${ }^{[17]}$, in which the incidence of Mirizzi syndrome was $1.07 \%$ in patients undergoing ERCP; this difference may be related to their (retrospective)study or a large sample size(656 cases) in comparison to our smaller study.

In this study jaundice duration was significantly longer among suspected tumor patients ( $\mathrm{P}$ value $=0.01$ ), which is comparable to a study done by Giuseppe Garcea et al ${ }^{[18]}$;

In this study the sensitivity of TAUS, MRCP/MRI, and EUS for detecting biliary diseases were 58\%, 60\%, and $96.1 \%$, respectively, which is comparable to a study done by Prachayakul et $\mathrm{al}^{[19]}$, in which the sensitivity of TAUS, MRCP, and EUS for detecting choledocholithiasis were 25$58 \%, 91 \%(33-100 \%)$, and 95\%, respectively.

The difference in the results may be related to many facts. First our study was broad included both benign \& malignant PBD that mean other pathologies which are included in the subset of biliary disease may have an impact on the result.Second in their study they depend on the likelihood (intermediate and high) for performing diagnostic modalities. Third in their study they declared a wide range of sensitivity of MRCP/MRI in detecting cholidocholithiasis, which related to the size of CBD stone, which may be a factor in our study too. Finally MRCP/MRI were done and reported by different radiologists in this study.

In this study, The specificity of TAUS, MRCP/MRI, and EUS for detecting biliary diseases were $42.8 \%, 50 \%$, and $65.2 \%$, respectively; in comparison to Prachayakul et al ${ }^{(19)}$ in which specificity of TAUS and EUS were $68-91 \%$, and $98 \%$, respectively; and the difference may also be related to the same factors mentioned earlier.

In one study done by H.E. Adamek et al ${ }^{[20]}$, the specificity of MRCP was $81 \%$. In another study done by De Ledinghen et al ${ }^{[21]}$ the sensitivity, specificity, positive predictive value 
(PPV), and negative predictive value (NPV) for suspected cholidocholithiasis (in 43 patients) were 100\%, 95.4\%, $90.9 \%$ and $100 \%$ for EUS, respectively; and $100 \%, 72.7 \%$, $62.5 \%$, and $100 \%$ for MRCP, respectively. In another study done by Chak A. et al ${ }^{[22]}$, the PPV and NPV of EUS for diagnosing choledocholithiasis (in 36 patients) were 100\% and $97 \%$, respectively.

In the current study; in addition to the aforementioned data the PPV and NPV of EUS for diagnosing biliary diseases were $86 \%$ and $83.3 \%$, respectively; and for MRCP were $75 \%$ and $33.3 \%$, respectively.

By comparing our study to the above mentioned studies we can estimate a wide variability in the accuracy of different diagnostic modalities especially EUS and MRCP for diagnosing biliary diseases, and this may indicate multiple factors contributing to such difference, including level of expertise in performing EUS, Un availability of specific guidelines for a better patient stratification and a time lapse between different studies, in addition to the sample size as mentioned before. One of the important factor which should be taken in to consideration is a spontaneous passage of gallstones in a period between performing EUS and ERCP, this is supported by a study done by Frossard et al ${ }^{[23] \text {, which }}$ reported that spontaneous passage of stones occurred at a rate of $20 \%$ per a week, especially if a stone very small $(<5 \mathrm{~mm})$ [24].

In this study the sensitivity, and specificity of TAUS for identifying pancreato-biliary tumor were $37.5 \%$, and $93.3 \%$; this is comparable to a study done by Chen et al ${ }^{[25],}$ in which a sensitivity of TAUS for detecting peri- ampullary tumor was $24 \%$. In another study done by Karlson et al ${ }^{[26]}$, the sensitivity and specificity of TAUS in the detection of all tumors in the pancreatic area were $88.6 \%$, and $98.8 \%$, respectively. This means TAUS is mostly operator dependent, and it needs a good expertise, but with comparable specificity to our study (because 7 out of 10 patients were diagnosed as pancreatic cancer).

The sensitivity, specificity, and accuracy of MRCP/MRI for diagnosing pancreatobiliary tumors in this study were $50 \%, 91.6 \%$, and $85.7 \%$, respectively, in comparison to a study done by Verma et al ${ }^{[27]}$, in which results were $86 \%$, $92 \%$, and $98 \%$, respectively; this indicate that sensitivity of MRCP/MRI were under question in both biliary diseases and pancreatobiliary tumors, and may be related in part to the poor technique of doing MRI/MRCP, as evidenced in an article written by Nayree Griffin et $\mathrm{al}^{[28]}$, in which factors behind a poor techniques declared in details like: (1) artefacts related to technique and reconstruction; (2) normal variants mimicking pathology; (3) intra-ductal factors; (4) extraductal factors.

In the current study the sensitivity, specificity, PPV, and NPV of EUS for identifying pancreatobiliary tumors were $84.6 \%, 97.7 \%, 84.6 \%$, and $97.7 \%$, respectively, which in comparable to a study done by Shoup M. et al ${ }^{[29]}$, in which the results of EUS for detecting peri-ampullary tumors were $97 \%, 33 \%, 94 \%$, and $50 \%$, respectively. In an article written by Gonzalo et al ${ }^{[30]}$ the sensitivity of EUS for detecting pancreatic tumor was $99 \%$ which is higher than in our study due to better experience in their study.

\section{Conclusion}

EUS is a valuable technique in both ( benign \& malignant ) pancreatobiliary diseases diagnosis \& evaluation before proceeding to further management by more invasive techniques like ERCP or surgery.

\section{Aknowledgement}

My sincere thanks to Dr. Dana Taib Garib and other colleagues whom helped me in couducting this study.

\section{References}

[1] David Q.-H. Wang, Nezam H. Afdhal. Gallstone Disease. In: Mark Feldman, Lawrence S. Friedman, Lawrence J. Brandt editors. 10th ed. Philadelphia. Elsevier Saunders; 2015. Sleisenger and Fordtran's Gastrointestinal and Liver disease. P 1100-1133.

[2] Laurent Palazzo, Anne Marie Lennon, Ian Penman. Endosonography. In: Jean Marc Canard, Jean-Christophe Létard, Laurent Palazzo, Ian Penman, Anne Marie Lennon editors. 1st ed. Edinburgh. Elsevier Churchill Livingstone; 2011. Gastrointestinal Endoscopy in Practice. P 274-369.

[3] Einstein D, Lapin S, Ralls P, et al. The insensitivity of sonography in the detection of choledocholithiasis. Am J Roentgenol 1984; 142:725-8.

[4] Barkun A, Barkun J, Fried G, et al. Useful predictors of bile duct stones in patients undergoing laparoscopic cholecystectomy. McGill Gallstone Treatment Group. Ann Surg 1994; 220:32-9.

[5] Caoili E, Paulson E, Heyneman L, et al. Helical CT cholangiography with three-dimensional volume rendering using an oral biliary contrast agent: Feasibility of a novel technique. Am J Roentgenol 2000; 174:487-92.

[6] Bortoff G, Chen M, Ott D, et al. Gallbladder stones: Imaging and intervention. Radiographics 2000; 20:751-66.

[7] Crabtree TD, Yacoub WN, Puri V, et al. Endoscopic ultrasound for early stage esophageal adenocarcinoma: implications for staging and survival. Ann Thorac Surg. 2011;91(5):1509-1515.

[8] John Meenan, Charles Vu. Equipment. In: Robert H. Hawes, Paul Fockens, Shyam Varadarajulu editors. 3rd ed. Philadelphia. Elsevier Saunders; 2015. Endosonography. P 1625 .

[9] Faris M. Murad, Mark Topazian. Indications, Preparation, and Adverse Effects. In: Robert H. Hawes, Paul Fockens, Shyam Varadarajulu editors. 3rd ed. Philadelphia. Elsevier Saunders; 2015. Endosonography. P 35-45.

[10] Michaels AJ, Draganov PV. Endoscopic ultrasonography guided celiac plexus neurolysis and celiac plexus block in the management of pain due to pancreatic cancer and chronic pancreatitis. World J Gastroenterol. 2007;13(26):3575-80. 
[11] Barish MA, Yucel EK, Ferrucci JT. Magnetic resonance cholangiopancreatography. N Engl J Med 1999; 341:258.

[12] Turowska A, Łebkowska U, Kubas B, et al. The role of magnetic resonance imaging (MRI) with magnetic resonance cholangiopancreatography (MRCP) in the diagnosis and assessment of resectability of pancreatic tumors. Med Sci Monit. 2007 May;13 Suppl 1:90-7.

[13] Bowie JD. Am J Gastroenterol. 2000 Apr;95(4):897-900.

[14] Niederau C, Sonnenberg A, Mueller J. Comparison of the extrahepatic bile duct size measured by ultrasound and by different radiographic methods. Gastroenterology. 1984 Sep;87(3):615-21.

[15] Ching-Ruei Hung, Ay-Chiao Huang, Yen-Chen Chen, et al. Common Bile Duct Diameter Measurement by Magnetic sensitivity, specificity and predictive values. Indian J Ophthalmol. 2008 Jan-Feb; 56(1): 45-50.

[16] Rajul Parikh, Annie Mathai, Shefali Parikh, et al. Understanding and using sensitivity, specificity and predictive values. Indian J Ophthalmol. 2008 Jan-Feb;

[17] Yonetci N, Kutluana U, Yilmaz M, et al. The incidence of Mirizzi syndrome in patients undergoing endoscopic retrograde cholangiopancreatography. Hepatobiliary Pancreat Dis Int. 2008; 7:520-4.

[18] Giuseppe Garcea, Wee Ngu, Christopher P. Neal, et al. Bilirubin levels predict malignancy in patients with obstructive jaundice. International Hepato- Pancreato-Biliary Association 2011; 13:426-430.

[19] Varayu Prachayakul, Pitulak Aswakul, Patommatat Bhunthumkomol,et al. Diagnostic yield of endoscopic ultrasonography in patients with intermediate or high likelihood of choledocholithiasis: a retrospective study from one university-based endoscopy center. BMC Gastroenterology 2014; 14:165.

[20] H E Adamek, J Albert, M Weitz, et al. A prospective evaluation of magnetic resonance cholangiopancreatography in patients with suspected bile duct obsruction. Gut 1998;43:680-683.
[21] De Lédinghen V, Lecesne R, Raymond JM, et al. Diagnosis of choledocholithiasis: EUS or magnetic resonance cholangiography? A prospective controlled study. Gastrointest Endosc 1999; 49:26-31.

[22] Chak A, Hawes R, Cooper G, et al. Prospective assessment of the utility of EUS in the evaluation of gallstone pancreatitis. Gastrointest Endosc 1999; 49:599 -604.

[23] Frossard JL, Hadengue A, Amouyal G,et al: Choledocholithiasis: a prospective study of spontaneous common bile duct stone migration. Gastrointest Endosc 2000, 51:175-179.

[24] Jean Marc Canard, Anne Marie Lennon, Jean-Christophe Létard et al. Endoscopic retrograde cholangiopancreatography. In: Jean Marc Canard, Jean- Christophe Létard, Laurent Palazzo, Ian Penman editors. Edinburgh. Elsevier Churchill livingstone; 2011. Gastrointestinal endoscopy in practice. P 370-465.

[25] Chen CH, Tseng LJ, Yang CC, et al. Preoperative evaluation of periampullary tumors by endoscopic sonography, transabdominal sonography, and computed tomography. J Clin Ultrasound.2001;29:313-21.

[26] Britt-Marie Karlson, Anders Ekbom, Per Gunnar Lindgren, et al. Abdominal US for Diagnosis of Pancreatic Tumor: Prospective Cohort Analysis. Radiology 1999; 213:107-111.

[27] Verma SR, Sahai SB, Gupta PK, et al. Obstructive JaundiceAetiological Spectrum, Clinical, Biochemical And Radiological Evaluation At A Tertiary Care Teaching Hospital The Internet Journal of Tropical Medicine 2011; 7(2).

[28] Nyree Griffin, Geoff Charles-Edwards, Lee Alexander Grant. Magnetic resonance cholangiopancreatography: the $\mathrm{ABC}$ of MRCP. Insights Imaging (2012) 3:11-21.

[29] Shoup M, Hodul P, Aranha GV, et al. Defining a role for endoscopic ultrasound in staging periampullary tumors. Am J Surg. 2000 Jun;179(6):453-6.

[30] Gonzalo-Marin J, Vila JJ, Perez-Miranda M. Role of endoscopic ultrasound in the diagnosis of pancreatic cancer. World J Gastrointest Oncol. 2014;15;6(9):360- 368. 